\title{
A novel mutation in a patient with insulin-like growth factor 1 (IGF1) deficiency
}

\author{
G Bonapace, D Concolino, S Formicola, P Strisciuglio
}

J Med Genet 2003;40:913-917

$\mathrm{T}$ he insulin-like growth factors (IGFs; somatomedins) comprise a family of peptides that play important roles in mammalian growth and development. The principal members of this family are IGF1 and IGF2. IGFI (somatomedin $\mathrm{C}$ ), a 70 residue basic polypeptide, mediates many of the growth promoting actions of growth hormone $(\mathrm{GH})$ and has metabolic and mitogenic effects. ${ }^{1}$ The major source of circulating IGFl is the liver, but it is also produced in a wide variety of tissues and has endocrine and paracrine modes of action. The mature IGFl peptide has A, B, C, and D domains with homology to insulin, and is highly conserved. ${ }^{2}$ It is produced as an inactive precursor, pre-pro-IGFl, with an additional carboxyterminal E region that plays an important role in the maturation of normal IGFl peptide. This regulatory region is obtained by alternative splicing of the last two exons. IGF1 resides on the long arm of chromosome 12 (12q 22-24.1), ${ }^{3}$ and several molecular studies have demonstrated that the structure of this gene is very complex. The gene contains six exons, which extend over more than $85 \mathrm{~kb}$ on chromosomal DNA. For human IGFl, two potential primary translation products exist: IGFIA and IGFIB, with sizes of 153 and 195 amino acids respectively. The two precursors are synthesised from distinct messenger RNAs produced by alternative splicing of the primary transcript. IGFlA mRNA contains exons 1, 2, 3, 4, and 6 of the human IGFI gene while IGF1B is encoded by exons $1,2,3,4$, and 5. It has been speculated that IGF1B plays the major role during intrauterine growth, while the same function during postnatal growth is taken over by IGFlA. ${ }^{4}$

Recent studies have focused attention on the genetic causes of growth alterations. Mutations involving the molecular structure of $\mathrm{GH}^{5}$ or the function of the $\mathrm{GH}$ receptor $^{6}$ have been described. Recently, a partial deletion of the gene for IGFl, resulting in intrauterine growth failure plus severe post-natal growth retardation, sensorineural deafness, and mental retardation has been found. ${ }^{7}$ In this study, we describe a new case of IGFl deficiency associated with sensorineural deafness, severe pre- and post-natal growth failure, and delayed psychomotor development produced by a novel transversion $\mathrm{T} \rightarrow \mathrm{A}$, which disrupts the normal consensus sequence for the polyadenylation site in the $3^{\prime}$ untranslated region of exon 6 of IGFI, leading to altered mRNA processing, which could account for the extremely low IGFl circulating levels and for the clinical findings.

\section{METHODS}

\section{Case report}

The patient was born at 39 weeks' gestation by caesarean section because of poor fetal growth. The pregnancy had until then been uneventful. The birth weight was $1480 \mathrm{~kg}(-4 \mathrm{SD})$, length was $41 \mathrm{~cm}(-6.5 \mathrm{SD})$, and the head circumference was $26.5 \mathrm{~cm}(<5$ th percentile). Hypoglycaemia and icterus were not reported. His parents were second cousins and the family history showed several miscarriages. His mother was

\section{Key points}

- We studied a new patient with short stature, sensorineural deafness, delayed psychomotor development, and IGFI deficiency.

- By direct sequencing and expression analysis we found this clinical condition associated with a novel transversion $T \rightarrow A$ in the $3^{\prime}$ untranslated region of exon 6 of the IGF1 gene. The mutation in the homozygous state resides on the consensus sequence AATATA of the polyadenylation site and leads to a deregulated IGFI mRNA maturation, altering the E domain of the IGFI precursor.

- We conclude that this novel mutation, in changing the normal amino acid sequence for the $E$ domain of the IGF1 precursor, accounts for the low circulating levels of IGF1 that causes the observed clinical condition.

$153 \mathrm{~cm}$ tall (5th percentile) and his father was $163 \mathrm{~cm}$ (5th percentile). His healthy sister, at the age of 9 years, was $120 \mathrm{~cm}$ tall $(-1 \mathrm{SD})$. The analysis of familial pedigree did not show the presence of a short stature condition segregating in the family. The clinical evaluation of the patient at the age of 19 months showed a weight of $4750 \mathrm{~kg}(-6.2 \mathrm{SD})$, a length of $64 \mathrm{~cm}(-6.2 \mathrm{SD})$, a head circumference of $40.5 \mathrm{~cm}(<5$ th percentile), a body mass index of 11.7 ( $>3$ rd percentile) and normal size genitalia. Delayed psychomotor development and poor responses to sound were noted.

To investigate the growth failure, tests were performed for thyroid and sexual hormones, anti-gliadin and anti-endomisium antibodies, and urine and plasma determination of amino acids and ammonia, in addition to karyotyping, radioimmunosorbent and radioallergosorbent testing, and the TORCH test for toxoplasma-rubella-cytomegalovirusherpes and other viruses. All were found to be normal. At the age of 19 months, the bone age according to Greulich and Pyle was in the neonatal range. Audiograms showed profound bilateral sensorineural deafness. At the age of 2 years a magnetic resonance imaging of the brain and skeletal $x$ ray were performed and found to be normal. The subsequent evaluation of the main growth regulator factors showed a basal GH serum concentration of $10 \mathrm{ng} / \mathrm{ml}$ with a peak after administration of arginine of $18 \mathrm{ng} / \mathrm{ml}$ (normal range $10-12 \mathrm{ng} / \mathrm{ml}$ ), and a basal low serum IGFl concentration of $1 \mathrm{ng} / \mathrm{ml}$ (normal range $3.7-152 \mathrm{ng} / \mathrm{ml}$ ). An IGFl generation test was performed according to the following

Abbreviations: $\mathrm{GH}$, growth hormone; IGFBP3, IGF binding protein 3; IGF, insulin-like growth factor; SSCP, single strand conformational polymorphism 
protocol: 0.6 IU GH/day were administered intramuscularly to the patient for 7 days. Starting from the eighth day, the IGF1 and the IGF binding protein 3 (IGFBP3) serum concentrations were evaluated weekly as described ${ }^{8}$ for 3 consecutive weeks. The IGFl serum levels did not change, whereas the serum basal IGFBP3 had been normal (3600 ng/ $\mathrm{ml}$ ) and did not change after the test $(3800 \mathrm{ng} / \mathrm{ml})$. The basal IGF l concentrations of the child's parents were in the lower adult normal range $(172 \mathrm{ng} / \mathrm{ml}$ and $159 \mathrm{ng} / \mathrm{ml}$ respectively, normal range $144-360 \mathrm{ng} / \mathrm{ml}$ ).

Informed consent was obtained from the patient's parents, and the study was approved by the ethics committee of the Faculty of Medicine of the University of Catanzaro.

\section{Molecular analysis}

DNA samples from normal controls, patient, and parents were extracted from whole blood by standard methods. Exons 1, 2, 3, 4, 5, and 6 of IGFI were amplified by PCR using nucleotide primer pairs designed on the basis of the published IGFI gene sequence (table 1). All of the primers were localised at $20 \mathrm{bp}$ from the intron-exon boundary. To analyse the promoter region we used two specific primers, PRf and PRr, designed according to the published sequence (GenBank accession no. N HSTGFACT-XSTO25.1). PCR amplification was performed using $100 \mathrm{ng}$ of genomic DNA in a $30 \mu \mathrm{l}$ volume with $250 \mu \mathrm{mol} / \mathrm{l}$ final concentration of dNTPs, a $1.5 \mathrm{mmol} / \mathrm{l}$ final concentration of $\mathrm{MgCl}_{2}, 10 \mathrm{pmol} / \mathrm{l}$ of each primer, and 1 U Taq DNA polymerase. After heating to $94^{\circ} \mathrm{C}$ for 3 minutes, 30 cycles were performed at $94^{\circ} \mathrm{C}$ for 1 minute, $55^{\circ} \mathrm{C}$ for 1 minute, and $72^{\circ} \mathrm{C}$ for 1 minute before a final step of $72^{\circ} \mathrm{C}$ for 10 minutes. Each PCR product $(15 \mu \mathrm{l})$ was electrophoresed on $1.8 \%$ agarose and visualised using ethidium bromide. The presence of point mutations in the IGFI gene of patient and parents was studied by single strand conformational polymorphism analysis (SSCP) using a semiautomatic electrophoresis unit (Genephor; Amersham Pharmacia Biosystems, Piscataway, NJ, USA). The runs were performed for 2 hours at $4^{\circ} \mathrm{C}$ and $250 \mathrm{~mA}$, and the gels were stained using an Amersham Pharmacia silver stain kit according to the manufacturer's instructions. The shifts detected were confirmed by a second set of PCR-SSCP experiments. The negative exons were analysed again using different gel conditions ( $10 \%$ acrylamide without glycerol, and $10 \%$ acrylamide plus $5 \%$ glycerol), to improve the sensitivity of the analysis.

RT-PCR was used to assess the effects of the novel identified mutation on mRNA transcription and maturation. Leukocytes from patient, parents, and controls were separated on a Ficoll 400 gradient. Cell pellets were lysed with 0.5 ml RNAzol B (Tel-Test Inc., Friendswood, TX, USA) and total RNA was isolated according to the manufacturer's instructions. This was treated with DNAse to eliminate the contaminant genomic DNA. Preparation of cDNA from total RNA was achieved using an RT system (Promega Corporation, Madison, WI, USA) and random priming. Human IGFI exon 6 was amplified from cDNA by 35 cycles of PCR using a gradient Master Cycler (Eppendorf, Barkhausen, Hamburg, Germany), two specific primers named RTf and RTr localised 20 bp into the exon, and the conditions described above. The RT products were subcloned using the Topo A TA Cloning system (Invitrogen, Carlsbad, CA, USA). Briefly, 4 ul of exon 6 RT-PCR product from patient, parent, and normal control cDNA were added to $1 \mu \mathrm{l}$ of Topo vector and $1 \mu \mathrm{l}$ of ligase salt solution. The final volume was made up to $8 \mu \mathrm{l}$. After 5 minutes of incubation at room temperature, the reaction was placed on ice; $2 \mu \mathrm{l}$ of the reaction were then transformed into ToploF competent cells according to the manufacturer's protocol. The cells were plated onto LB agar containing ampicillin, X gal and IPTG for

\begin{tabular}{ll}
$\begin{array}{l}\text { Table } 1 \\
\text { specific amplification }\end{array}$ \\
\hline Exon & Primer sequence $5^{\prime}-3^{\prime}$ \\
\hline IF & CAGACTITGAACTTCA \\
IR & GAATCCCCAATGAC \\
$2 F$ & TGGGCAGGTGAAGAT \\
$2 R$ & CTACTACTGAAATA \\
$3 F$ & CAGACAAGCCCACAGGGT \\
$3 R$ & GGTGGGCTACCTCTG \\
$5 F$ & AGTATCAGCCCCCAT \\
$5 R$ & ATGCATATAGAAGCCTA \\
$6 F$ & TATAGGAAGTACATTGA \\
$6 R$ & CAGAGAGGAATTAGTGC \\
\hline
\end{tabular}

white/blue colony screening. After incubation at $37^{\circ} \mathrm{C}$ for 24 hours, the white colonies were picked and cultured in LB broth at $37^{\circ} \mathrm{C}$ overnight. The Topo vector containing the exon 6 PCR product was purified by miniprep preparation according to the QiaQuick gel extraction Kit (Qiagen Inc, Valencia, CA, USA).

The sequencing analysis of the entire IGFI gene and of the SSCP positive products was performed by dideoxy chain terminator reaction using a Big Dye terminator kit according to the manufacturer's instructions (Amersham Pharmacia) and the same primers used for PCR. The RT PCR cloned products were sequenced using universal M13 forward and reverse primers. The sequences were then analysed using Fasta and Assembling softwares (Amersham Pharmacia). The point mutation thus identified was confirmed by the repetition of the test and comparison for overlap with the published wild type sequence (www.ncbi.nlm.nih.gov/; HSIGFACI-X57025.1 for the IGFI sequence, and HUMIGFBM37484.1 for IGFI exon 5 and 6 sequences). In a second group of experiments, we analysed 100 healthy controls from a comparable ethnic background with the same conditions to ensure that the mutation was not simply a polymorphism. For the RT-PCR cloning experiments, 15 clones from three diffe rent plates were sequenced. The resulting sequences were analysed with a Blast search (www.ncbi.nlm.gov./blast.cgi). The partial matching sequence $(>80 \%$ of homology) identified was the clone KIAA0537 (GenBank accession no. NM 014840.1 at locus NP055655, map 12q24.11).

\section{RESULTS}

Point mutations related to the clinical conditions in $I G F I$ were searched by PCR-SSCP and direct sequencing. After setting the more appropriate conditions in preliminary experiments on 30 unrelated healthy controls, $6 \mu \mathrm{l}$ of PCR products from each of the six exons from normal controls, the parents, patient, and his healthy sister were mixed with an equal volume of formamide denaturing gel loading buffer. They were then heat denatured and analysed on a $12.5 \%$ nondenaturing acrylamide gel. The PCR products showing an anomalous SSCP pattern were sequenced. As illustrated in fig 1, SSCP analysis of exon 6 showed a different migration pattern from the wild type, characterised by a double band for both parents (lane 2 and 5) and a single anomalous shifted band for the patient (lane 3 ). The signal for the patient's normal sister is shown in lane 4, and at the same position in lane 1 is the normal control. The promoter analysis of IGFI was negative, as was the repetition of the SSCP on the negative exons, in less stringent conditions (data not shown). Fig 2 shows the results of direct sequencing of exon 6 in the father (first lane), mother (second lane), and proband (third lane). The wild type sequence of IGFI gene from the databank is shown in the upper lane. The nonmatching zones are indicated by " $\mathrm{N}$ ". On the terminus of the 


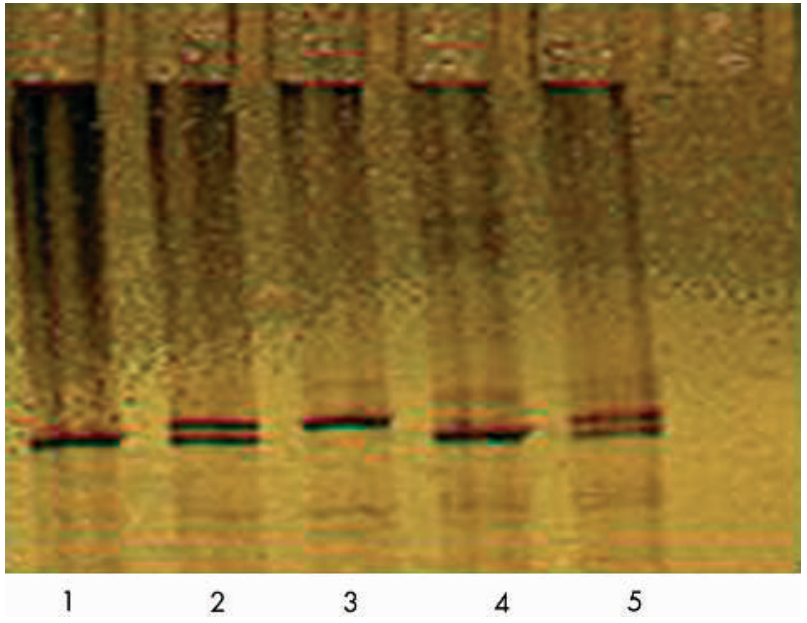

Figure 1 Single strand conformational polymorphism analysis of IGFI exon 6. Five ul of each PCR product from the various exon 6 IGFI amplifications were added to $5 \mathrm{ul}$ of $95 \%$ formaldehyde loading buffer, heat denatured, and run on a $12.5 \%$ acrylamide precast non-denaturing gel. A double band is present in lanes 2 and 5 for both parents of the proband. A single anomalous shifted band is evident in lane 3 (proband). The proband's sister (lane 4) shows a normal pattern, the same as the control in lane 1.

polyadenylation signal, AATATA, is a $\mathrm{T} \rightarrow \mathrm{A}$ transversion, heterozygous in both parents and homozygous in the proband. To confirm that this DNA variant was the causative mutation and not a generic polymorphism, we first performed a direct sequencing of the entire IGFl gene of the patient to exclude the presence of different molecular changes and then extended the sequencing analysis of exon 6 to the 100 unrelated healthy controls. No sequence alteration was found (data not shown). Notably, all members of the family lack the T nucleotide $2 \mathrm{bp}$ upstream of the mutation.

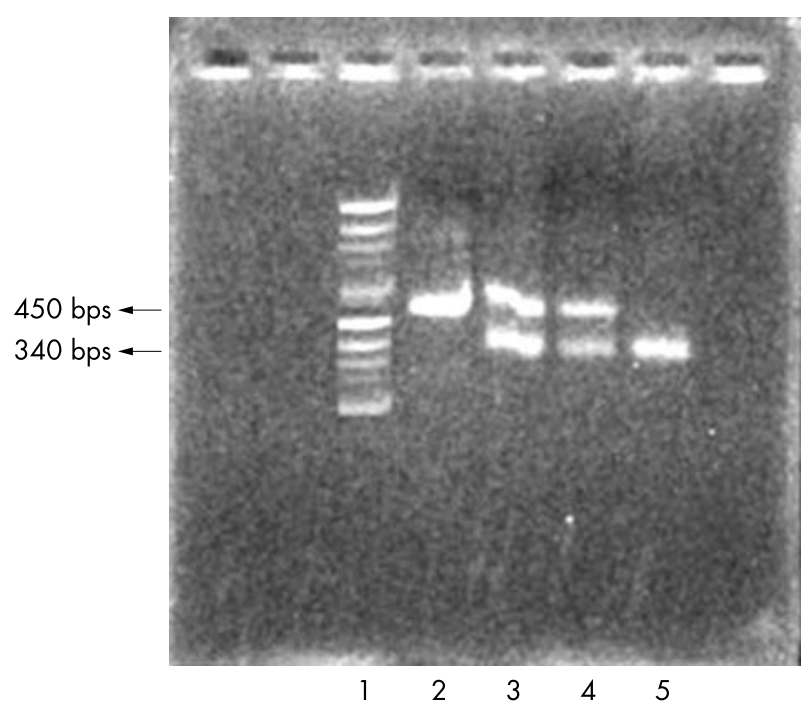

Figure 3 Expression analysis of exon 6 IGFI. After exon 6 cDNA specific amplification by RT-PCR, the products from the normal control (lane 2), father (lane 3), mother (lane 4), and patient (lane 5) were separated by electrophoresis on $2 \%$ agarose. Lane 1 contained $10 \mathrm{ul}$ of ФX174 Hinfl marker. The patient's lane shows a shorter band than the control, approximately $340 \mathrm{bp}$. The same band is present together with the normal allele of $450 \mathrm{bp}$ in both parents' lanes.

This situation is probably due to a familial silent polymorphism, as we were able to find the same condition only in the proband's healthy sister and not in other unrelated normal controls (data not shown). Finally, we performed molecular analysis on the GH receptor gene and were unable to find specific point mutations.

The effect of this novel mutation on the normal maturation of IGFl mRNA was evaluated by RT-PCR and specific

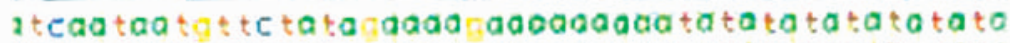
ATC AAT AAT TTCTATA AAAA AAAAAAAAA - ANAT AT AT AT AT AT A

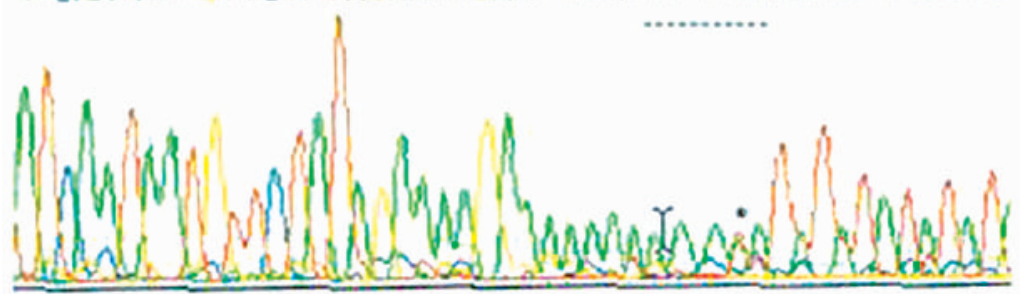

AT CAAT AATI T TCTATA IAAAAN AAAABAAAB - AN AT AT AT AT AT AT \&
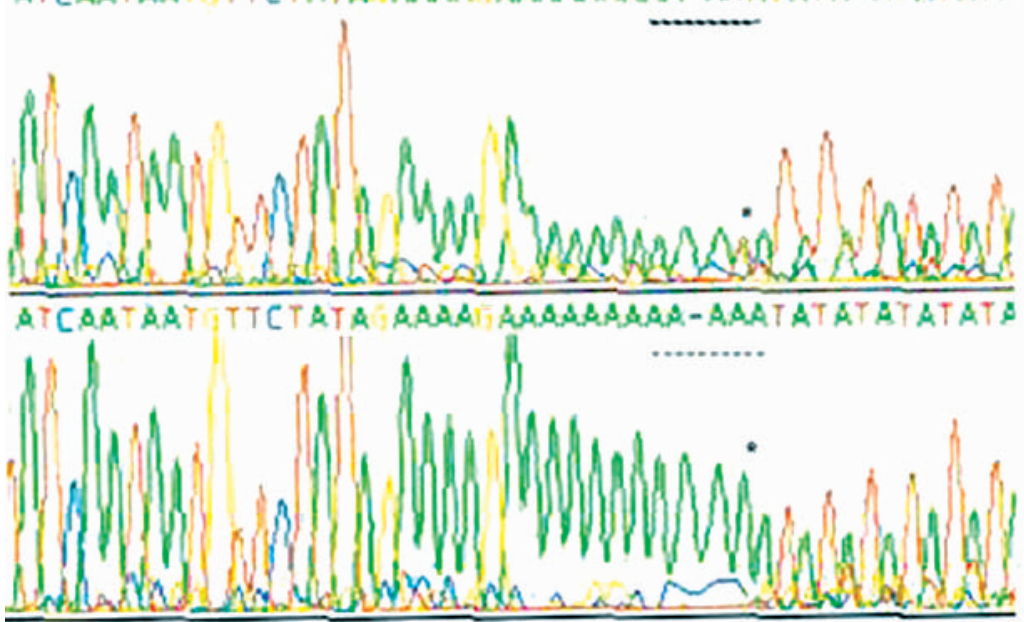

Figure 2 Sequence analysis of IGFI exon 6. Wild type IGFI sequence from the databank is shown in the upper line (lower case). The non-matching bases are indicated by " $\mathrm{N}$ ". The poly-A consensus sequences are underlined. *Indicates the $\mathrm{T} \rightarrow \mathrm{A}$ transversion: heterozygous in both two parents (lanes 1 \& 2) and homozygous in the proband (lane 3).

Mother

Proband 


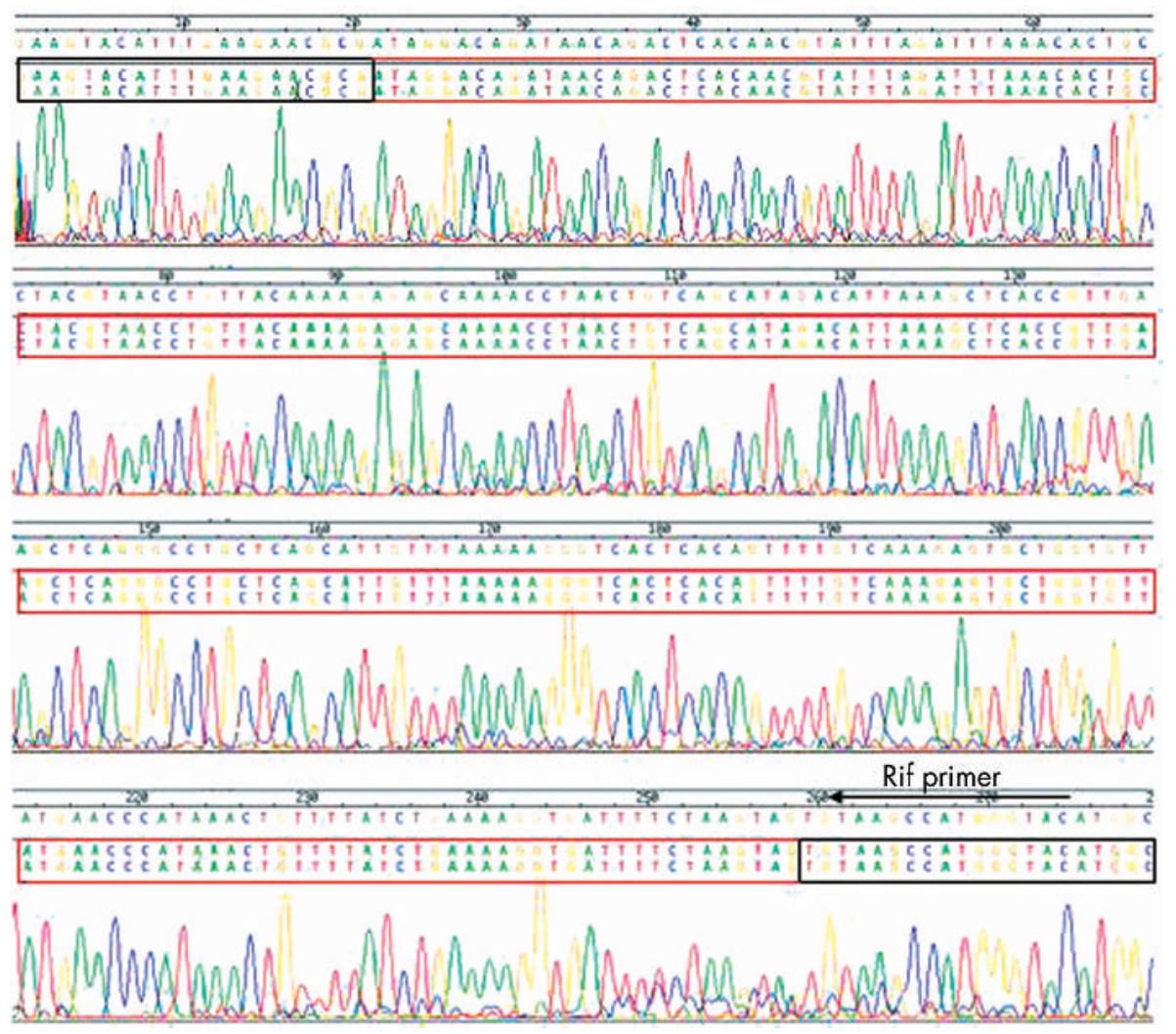

Figure 4 Direct sequencing of the exon 6 RT-PCR product. The black box shows the IGF1 exon 6 wild type sequence. After $20 \mathrm{bp}$, the sequence fuses with the KIAA sequence (red box). The terminal region of this sequence continues into the 3' IGF1 exon 6 sequence (black box). amplification of exon 6 from cDNA. Fig 3 shows the RT-PCR products of exon 6 separated on a $2 \%$ agarose gel containing ethidium bromide and visualised by ultraviolet light. Lane 2 is the normal control, lane 3 is the father, lane 4 the mother, and lane 5 the patient. There are clear differences between the product sizes of the patient and his parents; both parent's patterns show two bands of $450 \mathrm{bp}$ and $340 \mathrm{bp}$, with the upper band corresponding to the normal size of exon 6, whereas in the patient only the shorter band at $340 \mathrm{bp}$ is present. The anomalous $340 \mathrm{bp}$ band found in the expression experiments was sequenced after cloning into TOP $10 \mathrm{~F}$ vector system. Fifteen clones from four different plates were sequenced; fig 4 shows the resulting sequence. The mutant 5 ' exon 6 IGFI sequence diverges from that of the wild type, and the terminal region of this sequence continues onto the 3' IGFI exon 6 sequence. The Blast analysis of this anomalous intercalated sequence revealed a considerable homology to a clone KIAA0537 (Refseq accession NM 014840.1), localised downstream of IGFI on chromosome $12 .^{9}$ The RT-PCR primer position on the sequence is shown.

\section{DISCUSSION}

We describe a new case of IGFl deficiency, with severe preand post-natal growth failure, sensorineural deafness, and delayed psychomotor development. Our patient has a striking phenotypic similarity to the first IGFl deficiency case described by Woods et al. ${ }^{7}$ The clinical and biochemical findings showing an absence of response to the IGF 1 generation test in our patient prompted us to look for a possible specific defect in IGFl production after the exclusion of both GH and GH receptor deficiency. By molecular analysis, we discovered the presence of a novel mutation (transversion $\mathrm{T} \rightarrow \mathrm{A}$ ) on the polyadenylation signal AATATA in the $3^{\prime}$ untranslated region of $I G F 1$ exon 6, homozygous in the patient and heterozygous in the parents. The healthy sister presented a normal IGFI. By cloning and sequencing of RT-PCR IGFI exon 6 products, we demonstrated that the mutation disrupts the correct consensus sequence for the normal polyadenylation pathway and deregulates the splicing and the maturation of mRNA.

Several mechanisms have been proposed to control IGFI peptide production and action. It has been demonstrated that IGFl is bound to binding proteins while in circulation, and that this is the first step in the regulation of its action. ${ }^{10}$ IGF 1 transcription may determine how and where IGFl is active, and several start sites for transcription have been identified. ${ }^{11}$ Alternative splicing is another possible mechanism for the regulation of IGFI expression as has been suggested for other genes, such as the calcitonin/calcitonin related genes, in which different combinations of exons produce different peptides in different tissues. ${ }^{12}$ This idea has been recently confirmed by the observation that the new splice variant of IGFI present in human liver is obtained by the use of a cryptic $5^{\prime}$ donor splice site at the junction of exons 5 and 6 , confirming that in vivo cryptic sites are used to regulate the IGFl production. ${ }^{13}{ }^{14}$ In our patient, there is no evidence of alteration in IGF1 binding protein production, very low IGF 1 circulating levels are present, and the mutation resides on the IGFI gene region important for transcription and normal precursor processing. Therefore, we focused our attention on mRNA production and maturation as a possible functional target for the mutation. By quantitative RT-PCR (data not shown) we first assessed that the mutation does not affect the transcription rate of IGF1. By gel analysis of the RT-PCR products we found that in our patient the exon 6 product amplified from cDNA was shorter than normal (340 bp $v$ $450 \mathrm{bp}$ ). After cloning and direct sequencing of the RT PCR exon 6 product, we found that the initial part of the exon is fused to a sequence identified in the gene databank as clone KIAA0537, normally located downstream of IGFI, ${ }^{9}$ and 
consequently, all the normal codifying sequence of the exon was skipped. This was a surprising result. As it has been demonstrated that the normal polyadenylation signal on the $3^{\prime}$ region is important for the correct splicing of the mRNA, particularly to mark the $3^{\prime}$ end of the terminal exon, ${ }^{15}$ it could be speculated that because the novel mutation disrupts the polyadenylation signal, it may deregulate the normal scanning mechanisms by the splicing machinery of the intronexon junction, leading to an aberrant delayed splicing into the KIAA transcript. The most important functional consequence of the presence of the KIAA sequence into the $3^{\prime}$ terminal region of exon 6 is the complete alteration of the $\mathrm{E}$ domain of pre-pro-IGFl encoded by this exon, which plays a pivotal role in the maturation of the IGFl active peptide.

\section{CONCLUSION}

We believe our molecular data defining the first case of a homozygous defect in the polyadenylation signal of IGFI associated with severe pre- and post-natal growth failure, sensorineural deafness, and delayed psychomotor development are consistent with the fundamental role played by IGFI in normal growth and with the previously described pathways involved in the regulation of the active peptide. Specifically, we conclude that this novel mutation, disrupting the normal domain of the precursor required for the production of the active mature peptide, results in low circulating levels of IGF1, which causes the clinical condition observed in our patient, which also includes microcephaly and mental retardation. This is supported by several studies using transgenic mouse models, which showed effects on neuronal migration and oligodendrocyte differentiation, ${ }^{17}$ and have thus demonstrated the important role of IGFl in brain development.

\section{Authors' affiliations}

G Bonapace, D Concolino, S Formicola, P Strisciuglio, Department of Pediatrics, Faculty of Medicine, University Magna Graecia of Catanzaro, 88100 Italy

The first two authors contributed equally to this work.
Correspondence to: Pietro Strisciuglio, MD, Department of Pediatrics, University Magna Graecia of Catanzaro, c/o Ospedale Civile

A.Pugliese, Viale Pio X, 88100 Catanzaro, Italy; pstrisciuglio@unicz.it

\section{REFERENCES}

1 Lund PK. Insulin like growth factor I: molecular biology and relevance to tissue specific expression and action. Recent Prog Horm Res 1994:49:125-48.

2 D'Ercole AJ, Stiles AD, Underwood LE. Tissue concentration of somatomedin C: further evidence for multiple sites of synthesis and paracrine or autocrine mechanisms of action. Proc Natl Acad Sci USA 1984;81:935-9.

3 Brissenden JE, Ulrich A, Francke U. Human chromosomal mapping of genes for insulin like growth factors I and II and epidermal growth factors. Nature 1994;310:781-4.

4 Rotwein P, Pollock KM, Didier DK, Krivi GG. Organization and sequence of the human insulin like growth factor I gene. J Biol Chem 1986;261:4828-32.

5 Takahashi Y, Kaii H, Okimura Y, Goji K, Abe H, Chihara K. Short stature caused by a mutant growth hormone. New Engl J Med 1996;334:432-9.

6 Amselem S, Sobrier ML, Dastot F, Duqesnoy P, Durier B, Gosseus M. Molecular basis of inherited growth hormone resistance in childhood. In: Ross R, Savage MO, eds. Growth hormone resistance. London: Bailliere Tindall, 1996:353-69.

7 Woods KA, Camacho-Hubner C, Clark AJL, Savage MO. Intrauterine growth retardation and postnatal growth failure associated with deletion of insulin-like growth factor I gene. New Engl J Med 1996;355:1363-7.

8 de Boer H, Blok GJ, Popp-Snijders C, Stuurman L, Baxter RC, van der Veen E. Monitoring of growth hormone replacement therapy in adults, based on
measurement of serum markers. J Clin Endocrinol Metab 1996:1371-7.

9 Nagase T, Nakayama M, Nakajima D, Kikuno R, Ohara O. Prediction of the coding sequences of unidentified human genes. XX. The complete sequences of 100 new cDNA clones from brain which code for large proteins in vitro. DNA Res 2001, 27:8:85-95.

10 Baxter RC. Circulating binding proteins for the insulin like growth factors. Trends Endocrinol Metab 1993;4:91-6.

11 Lowe WL, Roberts CT, Lasky SR, Leroith D. Differential expression of the alternative 5'untranslated regions in mRNA encoding rat insulin like growth factor I. Proc Natl Acad Sci USA 1987;84:8946-50.

12 Rosenfeld MG, Mermod JJ, Amara SG, Swanson LW, Sawchenko PE, Rivier J, Vale WW, Evans RM. Production of a novel neuropeptide encoded by the calcitonin gene via tissue-specific RNA processing. Nature 1983;304:129-35.

13 Shern LC, Lavander PA, Clark AJ, Ross RJM. An alternatively spliced human insulin like growth factor I transcript with hepatic tissue expression that diverts from the mitogenic IBE I peptide. Endocrinology 1995;136:1939-43.

14 Sussembach JS, Steenbergh PH, Holthuize P. Structure and expression of the human insulin like growth factor genes. Growth Reg 1992;2:1-9.

15 Birnstiel ML, Bussilinger M, Strub K. Transcription termination and 3' processing: the end is in site. Cell 1985;41:349-59.

16 Lajara MR, Calgani JP, Dempsher DP, Bier DM, Rotwein P. Low prevalence of insulin like growth factor I gene mutations in human growth disorders. J Clin Endocrinol Metab 1990;70:687-92.

17 D'Ercole AJ, Ye P, Culikoglu AS, Gutierrez-Ospina G. The role of insulin-like growth factor in the central nervous system. Mol Neurobiol 1996; 13:227-55. 